\title{
Ripple effects in memory: Judgments of moral blame can distort memory for events
}

\author{
DAVID A. PIZARRO \\ Cornell University, Ithaca, New York \\ and \\ CARA LANEY, ERIN K. MORRIS, and ELIZABETH F. LOFTUS \\ University of California, Irvine, California
}

\begin{abstract}
Can judging an individual as being morally responsible for a negative act affect memory for details of the act? We presented participants with a story describing an individual (Frank) who committed a crime (he walked out on a restaurant bill). Some participants were told that the negative act was not intentional and that Frank was essentially a good person. Others were told that the negative act was intentional and that Frank actually enjoyed it. Control participants were given no extra information. All the participants then judged Frank's moral responsibility for walking out on the bill. When asked a week later to recall information about the event, the participants who had received negative information about Frank remembered that Frank had walked out on a larger restaurant bill than he actually had. Moreover, the degree of memory distortion was predicted by the degree of moral blame that had been attributed to Frank.
\end{abstract}

One of the more robust findings from the study of attribution is how readily we evaluate other individuals (Gilbert \& Malone, 1995). Social evaluations have the advantage of allowing us to organize our world along important dimensions (e.g., friends vs. foes). However, some social evaluations, such as blaming or praising, carry with them important consequences. At the most extreme, blame can lead to formal sanctions, such as imprisonment or death. Accordingly, psychologists have been interested in what sorts of factors people consider when making such evaluations.

A number of scholars (e.g., Shaver, 1985; Weiner, 1995) have outlined the various conditions generally deemed necessary for judging an agent to be worthy of blame for a particular action. Usually, these models describe the process of attributing blame as a rational one that occurs in stages, with the individual making a judgment about the act and the agent at each stage. For instance, an individual must determine the negativity and severity of an act, whether an agent possessed causal control over the outcome, whether the act was intentional, and whether or not there were mitigating factors involved.

These theories of blame draw heavily from the philosophical literature on moral responsibility (e.g., Arisotle);

This research was supported by NIMH Institutional Training Grant T32 MH19958-06. The authors thank the Loftus lab research assistants for their help in collecting data and Nancy Franklin, Kathleen B. McDermott, and Mara Mather for their helpful reviews. Correspondence concerning this article should be addressed to D. A. Pizarro, Department of Psychology, Cornell University, 211 Uris Hall, Ithaca, NY 14853 (e-mail: dap54@cornell.edu).

Note-This article was accepted by the previous editorial team, when Colin M. MacLeod was Editor. as such, they are normative, seeking to describe judgments of moral responsibility and blame made under ideal conditions (i.e., by a rational actor). Of course, social judgments are rarely made under ideal conditions; human beings possess motivations, beliefs, prejudices, and desires that may exert disproportionate influences on a variety of social judgments (Ditto \& Lopez, 1992; Kunda, 1990). Social judgments are also influenced by cognitive shortcomings, such as an overreliance on heuristics (Kahneman, Slovic, \& Tversky, 1982). For instance, lacking either the cognitive capacity or the motivation to think deeply about a problem often leads to an increased reliance on normatively irrelevant factors, such as the race or the attractiveness of an agent, as a heuristic for judgments across a variety of social domains, including judgments of criminal guilt (e.g., Bodenhausen, Sheppard, \& Kramer, 1994).

More important for the present discussion, it turns out that the same factors that bias social cognition can actually turn normative theories of blame on their head; spontaneous judgments of blame can shape the very perceptions that were supposed to have caused the judgment of blame (Alicke, 1992; see also Haidt, 2001; Haidt, Koller, \& Dias, 1993). For example, most normative models of blame propose that an individual must first take into account the degree of control an agent had over an outcome before assigning blame to that agent (Weiner, 1995). Under ideal conditions, this is exactly what occurs. In fact, individuals are capable of making very sophisticated distinctions among levels of causality, and these judgments clearly affect how they assign blame to an agent (Pizarro, Uhlmann, \& Bloom, 2003). But Alicke (1992) has cleverly demonstrated that rather than determining how much control an individual had over an outcome before assigning blame, 
individuals often first assign blame, then use the degree of blame they assigned as a heuristic for their judgment of how much causal control an individual had over the outcome. In one experiment, some participants were told that an individual was speeding home to hide an anniversary present from his parents, and other participants were told he was speeding home to hide cocaine from his parents. While speeding, he hit a slick surface and lost control of his car. When asked how much control the individual had over the accident, the participants who believed he was driving home to hide drugs attributed a greater degree of control over the outcome to the individual, presumably due to their effort to validate the blame they had attributed to a driver they perceived as morally deplorable. Alicke (2000) proposed that spontaneous evaluations of the sort described by Bargh and Chartrand (1999) likely lead individuals to engage in such blame validation - altering the evidential standards for blame, changing judgments of causation and control, and engaging in biased searches for evidence in favor of their judgment.

The process of blame validation may be strongest for judgments that are subjective in nature. So one reason blame might influence a judgment of control over an outcome is that it is difficult to reach an objective conclusion about the degree of causation or control an individual has over any given event. After all, a judgment of control is an inherently subjective estimate; even from a legal perspective, it is unclear how much causal responsibility for an outcome can be attributed to any one individual or act, since for any given act there exists a near infinite causal chain that contributed to the final outcome. Because these judgments are subjective, they may be more easily influenced by motivational factors or cognitive biases, such as a dislike of the blamed individual or the overuse of a stereotype (e.g., objectively defined traits are less susceptible to self-serving biases; Dunning, Meyerowitz, \& Holzberg, 1989; Gilovich, 1990).

\section{Can Social Evaluations Cause "Ripple" Effects on Memory?}

Numerous studies have shown that memory can be distorted (e.g., Ayers \& Reder, 1998; Loftus, 1997; Loftus \& Ketcham, 1994; Schacter, 1995, 2001). In particular, memory is susceptible to alteration as a result of postevent information (Loftus, 1979). Notably, postevent information is generally directed strategically toward the memories that the experimenter is attempting to distort. For instance, if the goal is to instill a false memory for the presence of a weapon at the crime scene, an experimenter may use leading questions that contain false information about a gun in the hands of the criminal. But there are a few cases in which postevent information can have more broad effects on memory than does the specific information presented in the postevent information. For example, in one study, participants were asked to recall the events in a video depiction of a car accident (Loftus \& Palmer, 1974). A single piece of false information was presented in a leading question: that the two cars had "smashed" into one another, rather than merely hitting each other. This information altered the participants' memories not only for the speed of the cars when they made contact, but also for related information, such as whether glass was broken in the course of the crash. This ripple effect, in which postevent information can influence a range of memories, not simply the specifics targeted with the postevent information, has also been demonstrated in other studies. For example, Wells and Bradfield (1999) gave eyewitnesses seemingly innocuous confirming feedback after they had picked a suspect from a mock lineup. This feedback made the eyewitnesses more confident in their choices, but it also affected other, related judgments, such as how good their initial views of the events were and how much attention they had paid to the events as they occurred.

However, in the present study, we posit that information about an agent may cause a distortion in memory for related details of an event (rather than the details of an event causing a misremembering for the memory source). Given what we know about the blame validation process, is it possible that postevent information about an individual's moral responsibility (a social evaluation that is neither false nor directly targeting any specific details about the event) can influence memory for the actual details of an event? Can blame validation processes influence not only subjective judgments about an event, but also memory for the objective details of the event? There is already evidence from the literature on memory and belief to suggest that such affective evaluations may be powerful enough to distort certain memories. For instance, when asked to recall the source of a negative statement, individuals are more likely to misremember negative statements as having been made by negative individuals (Cook, Marsh, \& Hicks, 2003). In this case, the socially valenced information caused details to be misattributed to a valence-consistent source. Could such valenced evaluations have a more broad effect, so that they distort related details for an event?

In the present study, we hypothesized that if participants judged a hypothetical character in a story as blameworthy, their recollections of a transgression described in the story would lead to a ripple effect, distorting the objective details of the event in the direction of attributing more negative characteristics to the actor's behavior.

\section{Overview}

Participants read a detailed story about an event in which an agent (Frank) engaged in a negative act (walking out on a restaurant bill without paying). The participants were then provided with postevent information about the agent's intentions, as well as about his overall character. Specifically, one group of participants was told that the agent in the story regularly engaged in similar questionable behavior and enjoyed taking advantage of others. Another group was told that the agent was a good person at heart and had left the bill unpaid because of extenuating personal circumstances. A third and final control group received no additional information about the agent. Approximately 1 week later, all the participants returned to 
the lab and were asked to recall specific details about the incident described in the initial session. We predicted that participants in the bad information condition would assign greater blame to Frank and would incorrectly remember Frank's transgression as more severe than it actually was.

\section{METHOD}

\section{Participants}

Two hundred eighty-three undergraduate students at the University of California, Irvine, participated in return for course credit.

\section{Materials and Procedure}

The participants were run in groups of up to 8 and participated in two separate experimental sessions (each lasting less than half an hour), held approximately 1 week apart. In the first session, all the participants, who believed that they were participating in an experiment about "judgment and attribution," read a story about a character named Frank, who had walked out of a restaurant without paying the bill for his meal. The story described in detail how Frank had eaten dinner at a restaurant alone, the various items he had ordered (e.g., drink, appetizer, main course, and dessert), and the price of the items he had ordered (the prices were those that might be found at a relatively upscale restaurant) and provided details about various apparently extraneous events about the night (such as that his cellular phone had rung toward the end of the meal). At the end of the night, Frank had left his table and walked out of the restaurant without paying for his meal. This story, given to participants in all the conditions, offered no reason as to why Frank had walked out without paying his bill (which amounted to $\$ 56.43$ ).

Manipulation. Immediately after reading the story about Frank, the participants received one of three sets of materials, each corresponding to our three manipulation groups. The participants in a no-information control group completed three pages of filler tasks. In contrast, after reading the same story, the participants in the good and bad information groups immediately completed only a single page of filler tasks but read an additional half-page of information about Frank. In the good information condition, the additional halfpage of information explained that Frank, a generally conscientious individual, had received a telephone call toward the end of his dinner alerting him to the fact that his daughter had been involved in an accident and had been seriously injured. In his state of shock and concern, Frank immediately had left the restaurant, completely forgetting to pay the bill on his way out. Later on that night, in the hospital, Frank had remembered that he had not paid his bill, so he immediately had called the restaurant and had left a message that told of his situation and that he was terribly sorry and would stop by at lunchtime to pay his bill.

In the bad information condition, the participants were told that Frank had been every waiter's nightmare. He had not only been obnoxious and picky about his order, but he had also treated the waiter rudely and had answered his cellular phone and engaged in a loud conversation with no consideration for those around him. In addition, the participants were told that Frank enjoyed walking out on his restaurant checks, doing so as much as he could, so long as he felt that he could get away with it. In this particular instance, Frank had taken a look at his bill, scanned the room to make sure that no one would notice him, and walked out on the bill purposefully, despite having more than enough money to cover the cost of the meal.

The purpose of the extra information was to encourage two different moral attributions: accentuated judgments of blame in the bad information condition and attenuated judgments of blame in the good information condition. In contrast, the control provided an appropriate comparison of judgments of blame for the events when no additional information was given.

Moral judgments. Immediately after reading the additional information about Frank (or in the case of the control group, im- mediately after the filler tasks), the participants completed a brief judgment task, which served as a measure of moral blame and as a check on the effectiveness of our manipulation. The participants were asked to judge, on 9-point scales, Frank's blameworthiness for leaving the restaurant without paying his bill (anchored by $1=$ none, $5=$ some, and $9=$ very $m u c h$, how negatively he should be judged as a person (anchored by $1=$ extremely positively, $5=$ neither positively nor negatively, and $9=$ extremely negatively), and the morality of his action (anchored by $1=$ extremely moral, $5=$ neither moral nor immoral, and $9=$ extremely immoral). After completing this task, the participants were excused for the day.

Upon returning the following week for the second session, the participants were given a surprise second judgment task and memory test. They were first asked the same three moral judgment questions about Frank as in the previous session (see above), in order to determine whether judgments of blame had become either more or less severe with the passage of time.

Memory items. The participants were then asked three openended recall questions and three multiple-choice recognition questions to assess their memory for the events of Frank's night at the restaurant that they had received during the first session. Specifically, the three open-ended questions asked the participants to recall the price of (1) the total bill, (2) the drink he had ordered before being seated, and (3) the dessert he had ordered. These three items were intended to constitute a general measure of memory for the single event (i.e., leaving without paying) when combined. The participants were then presented with three multiple-choice questions asking them to recall (1) how Frank had paid for his drink, (2) the price of the main entrée, and (3) the price of the total bill. When the judgment and memory tasks were completed, the participants were fully debriefed and excused.

\section{RESULTS}

\section{Moral Judgment Items}

Table 1 presents the mean ratings of blame (on 9-point scales; higher values indicate greater blame) for Sessions 1 and 2 (Cronbach's $\alpha=.93$ and .91, respectively). At both sessions, the participants who had received the bad information version of the Frank story judged Frank to be significantly more blameworthy than did those who had read the good information version, with the noinformation control group between the two [Session 1, $F(2,280)=534.22, p<.001$; Session $2, F(2,280)=$ $336.45, p<.001]$. Post hoc tests revealed that each group was significantly different from the other two at the $p<$ .001 level. A repeated measures ANOVA revealed that there was a significant effect of experimental session as well; this could be described as a cool-down effect: Moral judgments (both of blame and praise) were significantly more moderate at Session 2 than at Session 1 [that is, toward the midpoint of the scales, indicating greater neutrality; $F(1,280)=4.14, p<.05$ ], but this may simply have been due to a regression of the scores to the mean.

Table 1 Mean Ratings of Blame by Condition

\begin{tabular}{lccccc}
\hline & \multicolumn{3}{c}{ Session 1} & & \multicolumn{2}{c}{ Session 2} \\
\cline { 2 - 3 } \cline { 5 - 6 } Group & $M$ & $S D$ & & $M$ & $S D$ \\
\hline Good & 2.96 & 1.38 & & 3.46 & 1.36 \\
Control & 7.06 & 1.15 & & 6.68 & 1.18 \\
Bad & 8.14 & 0.85 & & 7.71 & 1.02 \\
\hline
\end{tabular}


Although the participants in the no-information control group attributed significantly less blame than did those in the bad information group, they still attributed significant blame to Frank. This makes sense; given no other reasons for Frank's behavior, it seems natural to assume that he had engaged in a blameworthy act.

\section{Memory Items (Recall)}

As was predicted, across all three price items - the total cost of the meal, the cost of the drink, and the cost of the dessert - the remembered price was greater in the bad information condition than in the good information condition, as revealed by a MANOVA $[F(6,520)=2.06, p<.06$; $\eta=.15$; see Table 2 for mean difference scores]. Follow-up ANOVAs revealed that this difference was driven largely by the participants in the bad information condition inflating the price of the dessert and the price of the drink.

One-sample $t$ tests revealed that the individuals in the good information condition did not significantly deviate from the actual price on any of the estimates (all $t$ values $<$ 1.1, n.s.). In comparison, the individuals in the control and bad information conditions consistently remembered prices as greater than they actually were ( $p$ values for these groups ranged from .01 to .09), demonstrating that those in the control and bad information conditions were less accurate [when the price estimates of the three items were converted to $z$ scores and combined to form one price index and this index was submitted to an ANOVA, there was a significant effect by condition as well; $F(2,274)=$ $3.40, p<.05 ; \eta=.16]$.

Another way to observe this distorted memory effect (although this method does not take into account the magnitude of distortion, which is provided by looking at the raw means) was to look at the proportion of responses involving overestimation for the three different price items. That is, we can categorize individuals into three groups: those who misremembered the price as higher than it actually was, those who provided an accurate response, and those who remembered the price as lower than it actually was. For the total price item, $34 \%$ of the overestimators were from the bad information condition, and $41 \%$ were from the control condition, whereas only $24 \%$ were from the good information condition $\left[\chi^{2}(2,268)=6.52, p<\right.$ $.05]$. Again, consistent with the observed judgments of blame, the control condition was more similar to (and slightly higher than) the bad information condition. The pattern was similar for the other two memory items (price of dessert and drink), although the $\chi^{2}$ statistic for the drink item was not significant.

Table 2

Difference Scores Between Remembered Prices and Actual Prices (in Dollars)

\begin{tabular}{lccc}
\hline Group & $\begin{array}{c}\text { Total Bill (Actual } \\
\text { Price }=\$ 56.43)\end{array}$ & $\begin{array}{c}\text { Dessert (Actual } \\
\text { Price }=\$ 6.50)\end{array}$ & $\begin{array}{c}\text { Drink (Actual } \\
\text { Price }=\$ 6.25)\end{array}$ \\
\hline Good & 2.80 & -0.14 & -0.05 \\
Control & 4.99 & 1.18 & 0.50 \\
Bad & 6.11 & 1.18 & 1.50 \\
\hline
\end{tabular}

If the degree of blame was related to the degree of memory distortion, this would be one source of evidence that the judgment of blame was responsible for the memory distortion. As was predicted, judgments of moral blame at both sessions were a significant predictor of memory for the amount of money Frank had walked out on. Specifically, the degree of blame the individuals assigned to Frank, across all conditions, was positively related to the overall prices on the three-item recall memory index. This was true for the judgments of blame (the averaged index of the three blame items) made at Session 1, as well as for those made at Session 2 (because these were correlated at $r(283)=.93$, for the purposes of this analysis, we combined the two ratings into one moral judgment index) $[r(277)=.15, p=.01]$.

\section{Memory Items (Recognition)}

Three additional questions used a multiple-choice format to assess memory for the cost of Frank's meal and other details of the story. The first question asked participants to select the actual price of the total meal. They were given eight options: Four were below the actual price, one was the actual price (which was \$56.43), two were above the actual price, and one was for "none of the above." The responses were collapsed into four categories (underestimations, correct answers, overestimations, and "none of the above"). The participants in the bad information group overestimated the price of the meal more than did those in the good information group $\left[\chi^{2}(3)=8.11, p<\right.$ $.05 ; n=19$ vs. $n=12]$. A second question addressed the cost of the main dish. Response choices included $\$ 9.35$, $\$ 13.95, \$ 23.95$ (the correct answer), and \$32.95. Contrary to our hypotheses, responses across these choices did not vary reliably by group $\left[\chi^{2}(6)=3.35\right.$, n.s.]. Finally, a third question asked the participants how Frank had paid for the Bloody Mary that he had ordered in the bar before he was seated. Responses across four choices ("he had it added to his restaurant bill," "he paid cash for it [the correct answer]," "he used a credit card," and "he didn't pay for it") did not vary by group $\left[\chi^{2}(6)=9.98\right.$, n.s. $]$. However, when comparing responses between the good and the bad information conditions on the correct response ("he paid cash for it") to responses for the most blameworthy response ("he didn't pay for it"), those in the bad information condition were slightly more likely to remember that Frank had failed to pay for the drink, whereas those in the good information condition tended to remember (correctly) that he had paid cash for it $\left[\chi^{2}(1)=2.82, p<.10\right]$.

\section{DISCUSSION}

We have presented evidence that a common social evaluation - in this case, a judgment of blame - can exert effects on memory for the objective details of an event. In the present study, receiving negative moral information about the agent in the story led the participants to misremember the amount of money the agent had failed to pay in the initial story (read 1 week earlier). Moreover, the 
degree of memory distortion was predicted by the amount of moral blame they attributed to the agent in this story.

Although Alicke (1992) has demonstrated the effects of judgments of blame on relatively ambiguous information (e.g., judgments of control over an outcome), similar processes may be strong enough to change memory for objective information (in this case, memory for a dollar amount that was presented to all the participants). The present findings thus represent an extension into the domain of memory of Alicke's (2000) theory of blame validation. In addition, the present findings represent a demonstration that social evaluations of a target can influence memory for the details of that person's actions. Although social beliefs about an individual have been demonstrated to affect memory - for instance, by distorting information about the source of the memory (e.g., Cook, et al., 2003; Mather, Johnson, \& De Leonardis, 1999) - the distorting of memory for the details of an event by providing misinformation that does not directly target those details has rarely been demonstrated - and to our knowledge, not by providing social information about an individual. Indeed, providing social information about an individual is a rather indirect strategy for altering memories, in comparison with the more direct strategies favored by researchers investigating misinformation effects (e.g., providing misinformation about a specific detail).

We should note that whereas Alicke's (2000) proposed explanation is an explicitly motivational one-individuals are motivated to seek evidence that is consistent with their desire to blame an individual - the finding presented here may be plausibly explained with little appeal to motivation. For instance, participants might infer that an individual with a questionable character, bent on taking advantage of restaurant owners, would seek out more expensive restaurants to walk out on. This inference might lead to the distorted recall of prices - a process less akin to a "hot" process of blame validation, and more like a top-down inference leading judgments of moral blame to influence other, related judgments for an action. ${ }^{1}$ Nonetheless, in either case, judgments of blame seem to be responsible for the observed distortion.

It is important to note that although the effects on memory reported in this study may not be on a large scale (the participants who were given negative information tended to inflate the initial prices between $10 \%$ and $25 \%$, as can be seen in Table 2), we take these findings as a demonstration that such negative evaluations are capable of exerting a distorting effect on memory. Our experimental design, after all, did not allow for a participant to be too unrealistic in his or her memory distortion (e.g., no one reported that Frank had murdered the waiter), nor was it the purpose of the present study to argue that such effects are common or severe. It is also possible that had our manipulation been stronger (i.e., providing information about an individual that was more strongly negative), we would have seen a larger effect on memory, in the range of the effect sizes that have been demonstrated in, for instance, the literature on valence effects on source monitoring (e.g., Cook et al., 2003).

Some questions remain, such as under what conditions social evaluations actually distort memory. Would negative judgments in unrelated domains or for unrelated events exert similar influences, or is it necessary to evaluate an individual on a moral dimension for such effects to occur (e.g., would a negative judgment about personal hygiene exert similar effects)? In addition, it may be the case that participants make an estimate of the price at the time of recall - that individuals believe the price to have been higher, rather than remembering a higher price. This possibility certainly justifies further research (such as asking participants whether they remember or know, or utilizing a think-aloud protocol during the time of recall).

Regardless of the underlying mechanism, some implications for memory distortion under these conditions still remain, such as on the accuracy of eyewitness testimony. Spontaneous evaluations made by an eyewitness about a defendant may influence their memories about the event in question-memories that often serve as the very data that judges and juries use as input for their judgments of guilt. In addition, if an eyewitness is presented with information about the moral character of an alleged perpetrator, even long after the events have occurred, his or her recall for the events in question (such as the severity of the crime) may be distorted, placing the alleged perpetrator in a position of disadvantage.

\section{REFERENCES}

Alicke, M. D. (1992). Culpable causation. Journal of Personality \& Social Psychology, 63, 368-378.

Alicke, M. D. (2000). Culpable control and the psychology of blame. Psychological Bulletin, 126, 556-574.

Ayers, M. S., \& Reder, L. M. (1998). A theoretical review of the misinformation effect: Predictions from an activation-based memory model. Psychonomic Bulletin \& Review, 5, 1-21.

BARgh, J. A., \& Chartrand, T. L. (1999). The unbearable automaticity of being. American Psychologist, 54, 462-479.

Bodenhausen, G. V., Sheppard, L., \& Kramer, G. P. (1994). Negative affect and social judgment: The differential impact of anger and sadness. European Journal of Social Psychology, 24, 45-62.

COOK, G. I., Marsh, R. L., \& Hicks, J. L. (2003). Halo and devil effects demonstrate valenced-based influences on source-monitoring decisions. Consciousness \& Cognition, 12, 257-278.

DitTo, P. H., \& Lopez, D. F. (1992). Motivated skepticism: The use of differential decision criteria for preferred and nonpreferred conclusions. Journal of Personality \& Social Psychology, 63, 568-584.

Dunning, D., Meyerowitz, J. A., \& Holzberg, A. D. (1989). Ambiguity and self-evaluation: The role of idiosyncratic trait definitions in self-serving assessments of ability. Journal of Personality \& Social Psychology, 57, 1082-1090.

Gilbert, D. T., \& Malone, P. S. (1995). The correspondence bias. Psychological Bulletin, 117, 21-38.

GiLovich, T. (1990). Differential construal and the false consensus effect. Journal of Personality \& Social Psychology, 59, 623-634.

HAIDT, J. (2001). The emotional dog and its rational tail: A social intuitionist approach to moral judgment. Psychological Review, 108, 814-834.

Haidt, J., Koller, S., \& Dias, M. (1993). Affect, culture, and morality, or is it wrong to eat your dog? Journal of Personality \& Social Psychology, 65, 613-628. 
Kahneman, D., Slovic, P., \& Tversky, A. (1982). Judgment under uncertainty: Heuristics and biases. New York: Cambridge University Press.

KNOBE, J. (2004). Intention, intentional action and moral considerations. Analysis, 64, 181-187.

Kunda, Z. (1990). The case for motivated reasoning. Psychological Bulletin, 108, 480-498.

LofTus, E. F. (1979). Eyewitness testimony. Cambridge, MA: Harvard University Press.

Loftus, E. F. (1997). Creating false memories. Scientific American, 277, 70-75.

Loftus, E. F., \& Ketcham, K. (1994). The myth of repressed memory: False memories and allegations of sexual abuse. New York: St. Martin's Griffin.

Loftus, E. F., \& Palmer, J. C. (1974). Reconstruction of automobile destruction: An example of interaction between language and memory. Journal of Verbal Learning \& Verbal Behavior, 13, 585-589.

Mather, M., Johnson, M. K., \& De Leonardis, D. M. (1999). Stereotype reliance in source monitoring: Age differences and neuropsychological test correlates. Cognitive Neuropsychology, 16, 437-458.

Pizarro, D. A., Uhlmann, E., \& Bloom, P. (2003). Causal deviance and the attribution of moral responsibility. Journal of Experimental Social Psychology, 39, 653-660.
SCHACTER, D. L. (ED.) (1995). Memory distortion: How minds, brains, and societies reconstruct the past. Cambridge, MA: Harvard University Press.

SCHACTER, D. L. (2001). The seven sins of memory: How the mind forgets and remembers. Boston: Houghton Mifflin.

SHAVER, K. G. (1985). The attribution of blame: Causality, responsibility, blameworthiness. New York: Springer.

WEINER, B. (1995). Judgments of responsibility: A foundation for a theory of social conduct. New York: Guilford.

Wells, G. L., \& BRADFIELD, A. L. (1999). Distortions in eyewitnesses' recollections: Can the postidentification feedback effect be moderated? Psychological Science, 10, 138-144.

\section{NOTE}

1. We thank Nancy Franklin for suggesting this possibility. We should note that similar findings regarding the effects of moral blame on judgments of the intentionality of an act have been subject to cognitive and motivational/emotional explanations, leading to quite a bit of debate (Knobe, 2004).

(Manuscript received September 27, 2004; revision accepted for publication April 29, 2005.) 